to turn a winning entry into a practical approach. Entrants may not have the motivation or the time for that.

Other established crowd-sourcing efforts, such as Galaxy Zoo and Foldit, are all about weight of numbers, not expertise: they enlist lay volunteers to conduct repetitive tasks - such as classifying galaxy morphologies or predicting protein structures - for which human judgement still out-performs automated solutions. This is useful, but is not going to lead to the kind of conceptual novelty that drives science forwards.

So although all the various approaches to harnessing the 'wisdom' (or perhaps just the labour) of the crowd have a part to play, there are surely lessons that other disciplines could learn from Polymath. One is the value of openness. The system is fully democratic: anyone can propose and coordinate a project, and if it is deemed to be worth the effort, anyone can pitch in with answers or suggestions, however small, which are judged purely on merit. "Anybody who had anything whatsoever to say about the problem could chip in," Polymath's creator Timothy Gowers explains. "You would contribute ideas even if they were undeveloped and/or likely to be wrong." Although it is perhaps not surprising that the challenges so far have been instigated by senior researchers, an ethos of this sort means that, in principle, the barrier to participation of younger, less experienced people is low.

And the process is a conversation, not a competition. It's not just, or even primarily, about cracking a problem, but about sharing ideas. "One strength is in gathering literature and connections with other fields that a traditional small collaboration might not be aware of without a fortuitous conversation with the right colleague," says Terence Tao, another of Polymath's coordinators. And participants are learning the effort's limits. "Projects that seem to require a genuinely new idea have so far not been terribly successful," says Gil Kalai of the Hebrew University of Jerusalem in Israel. That's one reason why he feels "it will be nice to have a Polymath devoted to theory-building rather than to specific problem-solving".

Preconceptions aside, it is perhaps not surprising that mathematicians are the first to approach crowd-sourcing in this way. Their field is relatively small and well connected, and not nearly as competitive as some might think. It has an active blogging community. And it faces problems that can be tackled online with digital pen and paper. It is less obvious "Sometimes it how, say, a chemistry challenge that demands lab work could be solved in this manner. But is that really the case? Some of the sucforces that cessful Polymath problems have been those achieve that could be broken down into smaller efficiencies, but parts that individuals could work on indecooperatives." pendently. An organic chemical synthesis is rather like that: a series of distinct steps between intermediates. The total synthesis of quinine was famously — and controversially — claimed in 1944 on that basis, when, rather than making the compound itself, Robert Woodward and William Doering bridged the last gap in a multi-stage process that had been largely completed by others. Might not these feats of synthesis be more systematically apportioned between several groups, swapping ideas, tips and techniques along the way? That could be much more efficient than the herculean efforts often doggedly pursued in single labs today, not least because there is less chance of going down blind alleys when many minds are involved. But it would require a change in the prevailing mentality of competition and victory that was evident, for example, in the total synthesis of taxol that was reported in 1994.

This is just one way in which crowd-sourcing need not be about letting a thousand flowers bloom and then throwing away all but the most fragrant, nor putting all hands to the pump. Sometimes it is not market forces that achieve efficiencies, but cooperatives.

\section{Virgin territory}

\section{Putting a private craft into space requires vision, hard work and a big dose of optimism.}

$\mathrm{L}$ ast week, Nature painted a pessimistic picture of the Google Lunar X Prize challenge in space exploration — which asks firms to land a robot explorer on the Moon by the end of next year. The technical hurdles are too high, critics say, and the financial incentives too low. A halfway house has been announced to offer encouragement: US\$6 million for groups that can demonstrate that their lander works on Earth by September this year (see Nature 506, 278; 2014).

By then, the X Prize model to encourage scientific progress could have launched its most successful venture yet. The word 'could' is pertinent, for the man talking up the chances of the venture is Richard Branson, the business tycoon with an ear for a catchy and ambitious sound bite. This is a man who does not do pessimism.

Branson said in the British newspaper The Guardian last week that the maiden flight of his private suborbital space-plane will blast off later this year - and that he and his family will be on board. We have been here before. Branson first promised that his company Virgin Galactic would start its space rides for paying customers in 2007, and it has been selling tickets for a decade.

He now says that work to launch the vehicle, SpaceShipTwo, is almost done. It is the successor to SpaceShipOne, which won the \$10-million Ansari X Prize for repeatable space flight with a manned craft in 2004, and for which Virgin bought the rights. And Branson is typically bullish about the craft's prospects. The re-entry technology, always the most risky part, is foolproof, he claims: "The pilot could be sound asleep on re-entry." Branson wants SpaceShipTwo to fly to the edge of space "100 times, maybe 1,000 times", he said.

SpaceShipOne hangs from the ceiling of the Smithsonian National Air and Space Museum in Washington DC, alongside the Spirit of St. Louis monoplane. SpaceShipTwo will have large windows, and white and silver seats. Engineers will customize those seats to the rears of the wealthy guests, to minimize the effects of $g$ force and to allow them to get the most of their estimated five minutes of weightlessness.

The Guardian spoke to astronaut Chris Hadfield, veteran of the NASA space shuttle and former commander of the International Space Station, who was sceptical of Branson's guarantees that nothing could go wrong. "To come into any programme with any vehicle and think you're somehow immune from what everybody else has always experienced with every machine in history is unrealistic," he said. "They don't know everything yet."

One thing that Branson does know (almost) everything about is how to keep a jumbo jet flying. As we report on page 420, that is more difficult than it sounds, particularly when the jet has a 2.5-metre infrared telescope sticking out of a hole in its fuselage. More than $\$ 1$ billion has so far gone into the modified Boeing 747, formally called the Stratospheric Observatory for Infrared Astronomy. After years of delays (sound familiar?) it is now fully operational, and could do some valuable science. And with annual running costs of $\$ 78$ million, it needs to.

There is something brilliantly simple about sticking a telescope on an aircraft as a way to beat atmospheric interference. But in 2014, doesn't such a solution seem a bit, well, twentieth century?

Back in the mid-1980s, Branson was invited by then Soviet leader Mikhail Gorbachev to become the first civilian in space. The ticket $\rightarrow$ NATURE.COM To comment online, click on Editorials at: go.nature.com/xhunqv would have cost $\$ 50$ million. "I thought," Branson said, "wouldn't it be better to spend that $\$ 50$ million building a spaceship company instead?" Optimism is not for everyone, but it has its benefits. 